\title{
EMOTIONAL INTELLIGENCE IN ALCOHOL DEPENDENT AND MENTALLY HEALTHY INDIVIDUALS: CASE- CONTROL STUDY
}

\author{
KS Sumi ${ }^{1 *}$, Varghese P Punnoose ${ }^{2}$, Nisha Cyriac ${ }^{3}$ \\ ${ }^{1}$ Junior Resident, ${ }^{2}$ Professor and Head, ${ }^{3}$ Assistant Professor \\ Dept. of Psychiatry, Govt. Medical College, Kottayam. \\ Correspondence: Dept. of Psychiatry, Govt. Medical College, Kottayam. E-mail: drsumiaswin@gmail.com
}

\begin{abstract}
Aim: To assess Emotional Intelligence in patients with alcohol dependence and compare it with that of mentally healthy individuals.

Materials and Methods: In this comparative cross-sectional study based on purposive sampling, 30 patients with alcohol dependence were selected from the Deaddiction Clinic of Govt. Medical College, Kottayam and 30 matched controls were selected from the bystanders in Medical and Surgical wards of the same institution. The diagnosis of alcohol dependence was based on ICD-10 DCR criteria. All participants were assessed with Mangal Emotional Intelligence Inventory. The study also examined the relationship between Emotional Intelligence and the age at onset of alcohol use. Obtained responses were scored by using standard scoring procedures and subsequently statistically analysed using SPSS version 22 .

Results: Patients with alcohol dependence were significantly deficient in all the areas of Emotional Intelligence. Lower scores in self-awareness were associated with younger age at onset of alcohol use.

Conclusion: Patients with alcohol dependence have significantly low Emotional Intelligence when compared with mentally healthy individuals.
\end{abstract}

Keywords: emotional intelligence, alcohol dependence, case-control study

\section{BACKGROUND AND RATIONALE}

Alcohol dependence is a heterogeneous disorder. Alcohol was reported as the second most commonly used substance after tobacco in National Survey on Drug Use and Health (NSDUH) on all the substance-related disorders. Stress can result in alcohol consumption which in turn results in further stress. Finding a preventive and effective treatment for alcohol dependence was always a challenge. ${ }^{1}$
The concept of Emotional Intelligence was first introduced by Salovey and Mayer in 1990, and it was initially defined as "a set of skills hypothesized to contribute to the accurate appraisal and expression of emotion in oneself and others, the effective regulation of emotion in self and others, and the use of feelings to motivate, plan, and achieve in one's life". ${ }^{2}$

Please cite this article as: Sumi KS, Punnoose VP, Cyriac N. Emotional Intelligence in alcohol dependent and mentally healthy individuals: Case-control study. Kerala Journal of Psychiatry 2017; 30(2):67-72. DOI: 10.30834/KJP.30.2.2018.56 
Emotional expression, and thus Emotional Intelligence, is affected by alcohol use. Emotional Intelligence has been thought of as a basis for success in life as it underlies a wide range of adaptive behaviours. Low Emotional Intelligence is associated with problems both at home and at work. Such individuals have difficulty in managing their emotions and are believed to be vulnerable to alcohol abuse. ${ }^{3,4}$ Craving as a withdrawal symptom at the beginning of treatment is reportedly high in alcohol dependent patients with low Emotional Intelligence. ${ }^{1}$

This study aimed to investigate the relationship between Emotional Intelligence and alcohol dependence and hypothesized that patients with alcohol dependence would have a lower level of Emotional Intelligence compared to individuals without mental and behavioural disorders. In patients with alcohol dependence, relation of the various components of Emotional Intelligence to the age at onset of alcohol consumption was also evaluated.

\section{METHODOLOGY}

Study Design: Cross-sectional comparative study Study Setting: Govt. Medical College, Kottayam. Study Period: $1^{\text {st }}$ April 2015 to $30^{\text {th }}$ June 2015 (three months).

\section{Study Population:}

Cases: Patients diagnosed with "Mental and behavioural disorders due to use of alcohol Dependence syndrome", using ICD-10 DCR criteria, without co-morbid psychiatric illness, from Deaddiction Clinic in Department of Psychiatry, Govt. Medical College, Kottayam.

Controls: Bystanders without mental and behavioural disorders selected from medical and surgical wards of Govt. Medical College, Kottayam.

\section{Inclusion criteria:}

1. Those diagnosed with "Mental and behavioural disorders due to use of alcohol — Dependence syndrome" according to ICD-10 DCR criteria.

2. Age above 18 years.
3. The minimum level of education should be an $8^{\text {th }}$ pass.

4. Those who have given written informed consent.

\section{Exclusion criteria:}

1. Those with major psychiatric disorders.

2. Those with organic brain disorders.

3. Those with mental retardation.

Sample Size: 30 cases and 30 controls. Sampling Method: Purposive sampling

Study Tools:

1. Sociodemographic and clinical data sheet: This semi-structured proforma was specially drafted for the study. It contained details of the sociodemographic variables, alcohol use, significant physical or psychiatric illnesses, and family history of psychiatric illnesses.

2. ICD 10 Classification of Mental and Behavioural Disorders- Diagnostic Criteria for Research: The Diagnostic Criteria for Research accompanying ICD-10 is the version used for research purposes. The content is derived from the glossary to the chapter on mental and behavioural disorders of ICD-10. It also provides the specific criteria for diagnoses that have been produced for general clinical and educational use by psychiatrists and mental health professionals.

3. Mangal Emotional Intelligence Inventory: The inventory was used to measure the Emotional Intelligence of the study subjects. It contains a total of 100 items, 25 each from the four aspects of Emotional Intelligence, namely intrapersonal awareness, interpersonal awareness, intrapersonal management, and interpersonal management. The subject has to respond either "yes" or "no" to each item. The responses were scored " 0 " or " 1 " depending upon the responses given, with the aid of the accompanying manual. Each of the four aspects was scored and rated as very poor (0-5), poor (6-10), average (11-15), good (16-20), or very good (21-25). For the total score, the rating was again very poor $(0-20)$, poor (21-40), average (41-60), good (61-80), or 
very good (81-100). Reliability of this test is 0.92 (test-retest method), and validity is 0.71 from the inter-validity formula. ${ }^{5}$ The inventory in English was translated to Malayalam by translation-retranslation method.

Study Procedure:

Patients diagnosed as having "Mental and behavioural disorders due to use of alcohol Dependence syndrome" from the Deaddiction clinic, Govt. Medical College, Kottayam were screened according to inclusion and exclusion criteria, and samples were selected for this study. Bystanders without mental and behavioural disorders were drawn from medical and surgical wards of Govt. Medical College, Kottayam.
The sociodemographic and clinical data sheet was filled after taking written informed consent of the subjects. Following the standard administration procedure, Mangal Emotional Intelligence Inventory was administered to all the subjects. After test administration, all protocols were scored according to the standard scoring procedure. The obtained responses were analysed by using the SPSS version 22.

\section{RESULTS}

The sociodemographic characteristics of the sample are given in Table 1. The mean age of the patients with alcohol dependence was $43.16 \pm 10.33$ years, and that of the controls was $42.63 \pm 10.42$ years.

Table 1: Sociodemographic characteristics of the sample

\begin{tabular}{|c|c|c|c|c|c|}
\hline VARIABLES & $\begin{array}{c}\text { ADS } \\
\text { GROUP }\end{array}$ & $\begin{array}{l}\text { CONTROL } \\
\text { GROUP }\end{array}$ & $\begin{array}{c}\text { CHI-SQUARE } \\
\text { VALUE }\end{array}$ & df & p-value \\
\hline \multicolumn{6}{|l|}{ Age } \\
\hline $20-30$ & 5 & 5 & \multirow[t]{3}{*}{.397} & \multirow[t]{3}{*}{2} & \multirow[t]{3}{*}{$.820(\mathrm{NS})$} \\
\hline $30-40$ & 8 & 6 & & & \\
\hline 41 and above & 17 & 19 & & & \\
\hline \multicolumn{6}{|l|}{ Education } \\
\hline $8^{\text {th }}-10^{\text {th }}$ & 26 & 25 & \multirow[t]{3}{*}{.353} & \multirow[t]{3}{*}{2} & \multirow[t]{3}{*}{$.838(\mathrm{NS})$} \\
\hline Intermediate & 1 & 2 & & & \\
\hline Graduation \& above & 3 & 3 & & & \\
\hline \multicolumn{6}{|l|}{ Marital status } \\
\hline Married & 26 & 25 & \multirow[t]{3}{*}{.220} & \multirow[t]{3}{*}{2} & \multirow[t]{3}{*}{.896 (NS) } \\
\hline Unmarried & 2 & 2 & & & \\
\hline Separated & 2 & 3 & & & \\
\hline \multicolumn{6}{|l|}{ Occupation } \\
\hline Employed & 15 & 16 & \multirow[t]{2}{*}{.067} & \multirow[t]{2}{*}{1} & \multirow[t]{2}{*}{$.796(\mathrm{NS})$} \\
\hline Unemployed & 15 & 14 & & & \\
\hline \multicolumn{6}{|l|}{ Residence } \\
\hline Urban & 16 & 16 & \multirow[t]{3}{*}{.000} & \multirow[t]{3}{*}{2} & \multirow[t]{3}{*}{$1.00(\mathrm{NS})$} \\
\hline Rural & 6 & 6 & & & \\
\hline Semi-urban & 8 & 8 & & & \\
\hline \multicolumn{6}{|l|}{ Religion } \\
\hline Hindu & 21 & 20 & \multirow[t]{3}{*}{2.083} & \multirow[t]{3}{*}{2} & \multirow[t]{3}{*}{$.353(\mathrm{NS})$} \\
\hline Muslim & 0 & 2 & & & \\
\hline Christian & 9 & 8 & & & \\
\hline
\end{tabular}

ADS: Alcohol Dependence Syndrome, NS: not significant 
Table 2: Emotional Intelligence and its subdomains of patients with alcohol dependence and controls.

\begin{tabular}{|c|c|c|c|c|c|}
\hline SUBDOMAINS OF EI & ADS & CONTROLS & $\begin{array}{c}\text { CHI- } \\
\text { SQUARE }\end{array}$ & df & $\mathrm{p}$ \\
\hline \multicolumn{6}{|l|}{ Intrapersonal awareness } \\
\hline Poor and very poor & 20 & 3 & \multirow[t]{3}{*}{20.383} & \multirow[t]{3}{*}{2} & \multirow[t]{3}{*}{$<0.001$} \\
\hline Average and good & 9 & 24 & & & \\
\hline Very good & 1 & 3 & & & \\
\hline \multicolumn{6}{|l|}{ Interpersonal awareness } \\
\hline Poor and very poor & 19 & 1 & \multirow[t]{3}{*}{24.726} & \multirow[t]{3}{*}{2} & \multirow[t]{3}{*}{$<0.001$} \\
\hline Average and good & 10 & 28 & & & \\
\hline Very good & 1 & 1 & & & \\
\hline \multicolumn{6}{|l|}{ Intrapersonal management } \\
\hline Poor and very poor & 24 & 2 & \multirow[t]{3}{*}{34.002} & \multirow[t]{3}{*}{2} & \multirow[t]{3}{*}{$<0.001$} \\
\hline Average and good & 4 & 25 & & & \\
\hline Very good & 2 & 3 & & & \\
\hline \multicolumn{6}{|l|}{ Interpersonal management } \\
\hline Poor and very poor & 18 & 2 & \multirow[t]{3}{*}{19.911} & \multirow[t]{3}{*}{2} & \multirow[t]{3}{*}{$<0.001$} \\
\hline Average and good & 10 & 26 & & & \\
\hline Very good & 2 & 2 & & & \\
\hline \multicolumn{6}{|l|}{ Total } \\
\hline Poor and very poor & 23 & 1 & \multirow[t]{3}{*}{35.292} & \multirow[t]{3}{*}{2} & \multirow[t]{3}{*}{$<0.001$} \\
\hline Average and good & 5 & 27 & & & \\
\hline Very good & 2 & 2 & & & \\
\hline
\end{tabular}

Table 3: Pearson's correlation coefficient between components of Emotional Intelligence and the age at onset of alcohol consumption in alcohol dependent individuals $(n=30)$.

\begin{tabular}{|l|c|c|}
\hline COMPONENTS OF EI & PEARSON CORRELATION & LEVEL OF SIGNIFICANCE \\
\hline Intrapersonal awareness & .348 & .05 \\
\hline Interpersonal awareness & .290 & .120 \\
\hline Intrapersonal management & .159 & .401 \\
\hline Interpersonal management & .142 & .453 \\
\hline
\end{tabular}


Nearly $85 \%$ of the subjects had an educational status of $8^{\text {th }}-10^{\text {th }}$ standard. Half were employed and belonged to an urban place. Most were married, and two- thirds were Hindus. No significant difference was found between the two groups on different sociodemographic variables.

On Mangal Emotional Intelligence Inventory, significant statistical difference was found between the groups in all subscales of Emotional Intelligence such as intra personal awareness for own emotions $(X 2=20.383, P<0.01)$, interpersonal awareness for others emotions $(X 2=24.726, P<0.01)$, intrapersonal management for own emotions $\left(X^{2}=\right.$ 34.022, $P<0.01$ ), interpersonal management for others emotions $(X 2=19.911, P<0.01)$, and aggregate emotional quotient $(X 2=35.292, P<$ 0.01) (Table 2).

Correlation between components of Emotional Intelligence and the age at onset of alcohol consumption was also examined. As described in Table 3, only the intrapersonal awareness subscale showed significant correlation with age at onset of alcohol consumption. Lower scores on interpersonal awareness were associated with younger age at onset of alcohol consumption (Table 3).

\section{DISCUSSION}

Emotional Intelligence refers to the awareness and management of emotions in self and others. ${ }^{2}$ High intelligence quotient is known to be associated with a high intellectual aptitude and in the same way, high socioemotional intelligence is correlated with above average mental health. ${ }^{6}$ This study compared Emotional Intelligence in patients with alcohol dependence to mentally healthy controls.

The study showed that a significantly higher proportion of alcohol dependence patients has deficits in all components of EI as compared to controls. A similar study conducted among college students, which included substances other than alcohol, proved a significant relationship between Emotional Intelligence and the likelihood of drug addiction among students. ${ }^{7}$ A study with findings inconsistent to our findings was that by Saklofske et al. which examined associations between Emotional Intelligence and health behaviours in Canadian students and proved that there is no relationship between alcohol consumption and Emotional Intelligence. ${ }^{8}$

We also examined the relationship between Emotional Intelligence subscales and age at onset of alcohol consumption. It was found that only intrapersonal awareness subscale had a significant relationship, which was consistent with the study by Mohagheghi et al. ${ }^{1}$ Evidence indicates that those who become dependent on drugs and/or alcohol are not able to understand or express their feelings and are unable to cope with their odd feelings, and as a result, they seek drugs. It is proposed that they use drugs to deal with their unknown stresses and discomforts. ${ }^{\text {? }}$

Studies by Benjamin and Wulfert, ${ }^{10}$ and Clark et al. ${ }^{11}$ propose that interpersonal relations may considerably improve individual capacities by providing a social support to deal with environmental stresses. Our study too revealed significant deficits in interpersonal and intrapersonal components of Emotional Intelligence in patients with alcohol dependence.

Higher Emotional Intelligence, and thus a higher mental ability for processing social cues and pressures, may help individuals to better understand the harmful consequences of alcohol consumption and to effectively deal with such kinds of stresses. ${ }^{12}$ Our study was found to support these observations.

\section{LIMITATIONS}

The sample size was small, and all the participants were males. Furthermore, the data are crosssectional rather than longitudinal, and therefore, the findings cannot be used to attribute causal relationships.

\section{CONCLUSIONS}

Patients with alcohol dependence are lacking in all four components of EI. It might be effective to identify and train the individuals with lower scores 
in these aspects of Emotional Intelligence to prevent alcohol-related problems. Future studies should include a larger sample, include both sexes, aim for longitudinal studies, and try to include the effect of other factors like coping skills.

\section{REFERENCES}

1. Mohagheghi A, Amiri S, Mousavi Rizi S, Safikhanlou S. Emotional intelligence components in alcohol dependent and mentally healthy individuals. ScientificWorldJournal 2015; 2015:841039.

2. Salovey P, Mayer JD. Emotional intelligence. Imagin Cogn Pers 1990; 9(3):185-211.

3. Coelho KR. Emotional intelligence: An untapped resource for alcohol and other drug related prevention among adolescents and adults. Depress Res Treat 2012; 2012:281019.

4. Prakash O, Sharma N, Singh AR, Sengar KS, Chaudhury S, Ranjan JK. Personality disorder, emotional intelligence, and locus of control of patients with alcohol dependence. Ind Psychiatry J 2015; 24(1):40-7.

5. Mangal SK, Mangal S. Manual for Mangal Emotional Intelligence Inventory. Agra: National Psychological Corporation; 1985.

6. Vaillant GE, Vaillant CO. Normality and Mental health. In: Sadock BJ, Sadock VA, Ruiz, P. (Eds). Comprehensive textbook of Psychiatry $9^{\text {th }}$ ed. Philadelphia: Williams and Wilkins; 2009. pp. 692-706.

7. Sharma MM. The relationship between emotional intelligence and abuse of alcohol, marijuana, and tobacco among college students. Journal of Alcohol and Drug Education 2012; 56(1):8-37.

8. Saklofske DH, Austin EJ, Galloway J, Davidson K. Individual difference correlates of health-related behaviours: Preliminary evidence for links between emotional intelligence and coping. Personality and Individual Differences. 2007;42(3):491-502.
9. Ciarrochi JE. Emotional Intelligence in Everyday Life, vol. 2. New York: Psychology Press; 2001.

10. Benjamin L, Wulfert E. Dispositional correlates of addictive behaviors in college women: binge eating and heavy drinking. Eating Behaviors 2005; 6(3):197-209.

11. Clark L, Robbins TW, Ersche KD, Sahakian BJ. Reflection impulsivity in current and former substance users. Biol Psychiatry 2006; 60(5):515-22.

12. Mayer JD, Salovey P. What is emotional intelligence? In: Salovey P, Sluyter D. (Eds.), Emotional Development, Emotional Literacy, and Emotional Intelligence. New York: Basic Books; 1997. pp. 3-31.

Source of support: None

Conflict of interest: None declared

First submitted: $5^{\text {th }}$ October 2016

Published online: $11^{\text {th }}$ January 2018 